\title{
Long-term drivers of broadband traffic in next-generation networks
}

\author{
P. Loskot • M. A. M. Hassanien • F. Farjady • M. Ruffini • \\ D. Payne
}

Received: 27 July 2013 / Accepted: 9 January 2014 / Published online: 13 February 2014

(C) The Author(s) 2014. This article is published with open access at Springerlink.com

\begin{abstract}
This paper is concerned with long-term (20+years) forecasting of broadband traffic in next-generation networks. Such long-term approach requires going beyond extrapolations of past traffic data while facing high uncertainty in predicting the future developments and facing the fact that, in 20 years, the current network technologies and architectures will be obsolete. Thus, "order of magnitude" upper bounds of upstream and downstream traffic are deemed to be good enough to facilitate such long-term forecasting. These bounds can be obtained by evaluating the limits of human sighting and assuming that these limits will be achieved by future services or, alternatively, by considering the contents transferred by bandwidth-demanding applications such as those using embedded interactive 3D video streaming. The traffic upper bounds are a good indication of the peak values and, subsequently, also of the future network capacity demands. Furthermore, the main drivers of traffic growth including multimedia as well as non-multimedia applications are identified. New disruptive applications and services are explored that can make good use of the large bandwidth provided by next-generation networks. The results can be used to identify monetization opportunities of future services and to map potential revenues for network operators.
\end{abstract}

P. Loskot $(\bowtie) \cdot$ M. A. M. Hassanien

College of Engineering, Swansea University, Singleton Park,

Swansea SA2 8PP, UK

e-mail: p.loskot@swan.ac.uk

F. Farjady

Aston Institute of Photonic Technologies, Aston University, Aston

Triangle, Birmingham B4 7ET, UK

M. Ruffini $\cdot$ D. Payne

CTVR, Dunlop Oriel House, Trinity College, University of Dublin,

Dublin, Ireland
Keywords Broadband services · Next-generation networks · Network operator · Traffic growth drivers · Traffic forecasting $\cdot$ Video streaming

\section{Introduction}

Businesses are increasingly dependent on the state-of-the-art communication systems. Therefore, it is important that the rural as well as remote areas have the same services and capabilities as the urban areas. Provided that the businesses are not restricted by the availability and capabilities of the communication infrastructure, for instance, provided that the network operators can flexibly assign and reassign the network resources to subscribers based on their current demand, the businesses can spring up and flourish anywhere, and even the sparsely populated areas are likely to attract the inward investments. GDP growth, inward investments, stimulation of new entrepreneurships and businesses, and other measures of economic activity are known to be important economic and commercial drivers of deploying next-generation networks (NGN). The reports by the Organisation for Economic Cooperation and Development (OECD) in Europe and by the Office of Communications (Ofcom) in the UK show high correlations between offerings of the broadband services in a geographical area and its GDP growth [22, 31].

In general, there is interplay between the content providers and the bandwidth (i.e. network) providers; each of them represents a distinct market. Youtube is a good example of co-evolution between the content and network providers whereas the iPlayer from BBC proves that there exist occasional disruptions of the natural growth. The broadband networks are a long-term investment [41]; for instance, it will take at least next 10-15 years to fibre the whole UK. The network providers invest into the network expansion just ahead of the (permanently) increasing bandwidth demand. 
Hence, forecasting of the future network services [5] is extremely valuable for the network operators who are especially concerned to identify important drivers of traffic in NGN.

In general, we need to study future broadband services to show that the subscribers can make good use of the extra bandwidth provided by the new NGN technologies such as fibre-to-the-cabinet (FTTC) and especially fibre-tothe-premises (FTTP) and that these technologies can be also justified by the expected benefits to the community $[6,10]$. The large bandwidth offered by NGN will provide new service monetization opportunities. For example, renting the processing power within the cloud computing service model motivates deployment of fast broadband connections to the customer premises while allowing to exploit the high bandwidth which will have a positive impact on the revenues for the network operator. In addition, the available bandwidth can be partitioned and flexibly rented on demand for remote processing and cloud computing applications. The dedicated portions of the available bandwidth can be utilized to support different service classes, to simplify traffic management and monitoring by isolating different types of traffic and to create new service bundling options that can be offered to the subscribers. For instance, local loop unbundling (LLU) offered by $\mathrm{BT}$ enables other communication service providers to install their equipment at the BT's exchanges or nearby in order to connect the customers' lines or local loops to the communication provider's own network.

Even though many broadband services do not generate any revenues for the network providers, identifying opportunities for monetization of services in NGN is very valuable. The models of broadband services have become more complex over time [19], and currently, these models incorporate issues such as bonding, vectoring, and packaging of services. Thus, the offered services drive development of traffic models which are then used to map potential revenues [17]. For instance, open service models drive regulatory models which in turn drive business models including monetization of broadband services.

Traffic models can be used to generate artificial traffic data, for example, for evaluation of different network architectures by computer simulations. Traffic volume is often driven by a single emerging factor which usually weakens over time, and traffic saturates. Thus, traffic models should produce the logistic curves rather than follow the exponential growth curves [39]. Public sources of broadband traffic data are very useful for developing and validating traffic models. Some recommended sources of publicly available traffic data are as follows: in the UK, the House of Lords government report by the Head of Strategy; in Europe, the reports provided by OECD and Ofcom; and also the reports usually published by the national network operators and regulators. The latter contain traffic data at network exchanges which can be used to accurately predict traffic growth in the whole country. However, the key for understanding these traffic data reports are the assumptions and measurement conditions that were used to generate the reported data. Traffic models are usually built assuming some key parameters and factors such as analysis of historical data, the number of broadband connections per exchange, adoption and usage rates of applications, statistical behaviour of subscribers, processing capabilities of end-hosts, access speeds of broadband connections and so on. In addition, it is useful to classify values of the underlying traffic model parameters as being either conservative, optimistic or an upper bound.

There are also other public sources of broadband traffic data. In particular, the MINTS [28] project collated the Internet traffic growth rates for different regions around the world including Western Europe in years 2002-2009. The yearover-year (YoY) traffic growth rates are predicted by linear least squares fitting of historical traffic data [26]. However, since such analysis assumes aggregated (i.e. average) traffic data, extrapolation of these results to different countries is limited. Assuming traffic data of the Internet service providers (ISP) in Japan, Cho et al. [8] suggest that video services will not significantly affect overall traffic in the near future whereas these services will eventually reshape traffic in broadband networks in a longer term. The traffic reports produced by FTTH Council Europe [16] contain forecasted traffic data for Europe for the following 5 years. The paper [21] predicts streaming video traffic over the period 2010-2015.

Cisco Visual Networking Index (VNI) [9] provides detailed traffic forecasts over the next 5 years for different regions and countries. These traffic forecasts are used extensively in many published research works. In the first step, the number of users and broadband connections and their types are estimated using traffic data from broadband regulators. The application adoption and usage rates are then estimated for each application and service type using traffic data from the service providers and using the customers' surveys. The average traffic data are calculated by multiplying the bitrates of applications and services with their anticipated usage times and the number of subscribers. The traffic estimates for the core Internet, the managed ISP and the mobile subscribers are reconciled by assessing traffic migration between the segments of the broadband network. Finally, in the last step, the obtained traffic forecasts are validated using the actual YoY traffic growth data following by possible readjustments of the traffic estimates in each step. It should be noted that Cisco VNI only reports the sources of traffic data used; however, the actual data used are not provided.

For example, the Ministry of Japan estimates the total annual broadband traffic to be 0.5 exabyte in 2010 while Cisco VNI traffic forecast is 0.6 exabyte for Japan in 2010. For the UK, the Cisco VNI forecasts have not been verified. The Cisco traffic data would have to be rescaled to account for specifics of the different UK regions since traffic usage 
patterns in these regions are different. For instance, Wales has a medium take-up of broadband services which is nevertheless higher than that in Scotland, but lower than those in Northern Ireland and England. However, the reported take-up growth rates in Wales in 2009-2010 are higher than those in England and comparable to those in Northern Ireland while most of this take-up is happening in the rural areas. In addition, the main Internet protocol television (IPTV) provider in the UK Tiscali did not provide its services in Wales until 2009 although it already did in other parts of the UK.

The main aim of this paper is to explore evolution of broadband traffic over a 20 -year perspective into the future even though the current network technologies are likely to be obsolete by then [41]. We will also attempt to identify disruptive services that will spur new bandwidth demands. The longterm traffic predictions can be obtained by evaluating the limits of human senses (especially sighting) and then assuming that these limits will be achieved by future services. Alternatively, we will consider the likely contents to be transferred over the future broadband networks to form the upper bounds of traffic.

\section{Building long-term traffic models}

Broadband traffic is usually characterized by the sustained data rates, whereas the traffic peak values are a good indication of the potential network capacity demands for the broadband network dimensioning purposes. We can aim at characterizing the traffic dynamics either at the network core or at the network edges [7]. The latter is more challenging since traffic at the network edges experiences more variations, and thus, it is more difficult to forecast than traffic at the network core.

It is useful to distinguish between short-term and long-term traffic modelling and analysis [40]. The short-term traffic analysis usually employs statistical methods such as regression $[1,26]$, whereas the long-term traffic analysis is dominantly affected by the network technology used as well as by the various economic and demographic factors [2]. There are different methodologies to forecast broadband traffic [24, 32, 43]. The models commonly used in the relevant projects and in the open literature are judgemental, i.e. they assume that past traffic is a good indication of future traffic [39, 40, 46]. Other often used traffic models are the time-series models that assume periodic traffic measurements in order to update the judgemental models. A great challenge common to all these models is the availability of traffic data [3] which is usually rather limited due to political, legal, business and other reasons [40]. However, the publicly available traffic data from the government and the regulator sites can give good indication about the broadband traffic trends over the past several years.
Our approach to long-term traffic forecasting assumes the upper bounds of future traffic. The traffic upper bounds can be constructed by considering how much information content an average person is able to absorb at most. Traffic in future networks will be dominated by $3 \mathrm{D}$ video (currently, there is no 3D standard, but it is very likely that eventually such standard will be adopted), the Internet storage and other services in the cloud. The future multimedia delivery is likely to be point-to-point (Pt-Pt), thus moving traffic from the network core to its edges. The Pt-Pt services and other nonmultimedia applications will be driving the bandwidth requirements especially in the upstream even though the downstream and upstream traffic volumes have a tendency to become more balanced over time.

The video-based applications and services are expected to be the strongest driver of the future traffic growth and even exceed the bandwidth demands of the file-sharing services. Moreover, some of the existing services are likely to be enhanced with embedded video; the upcoming merge of MSN with Skype is one such example. The human eye perception and emulation of the real-life vision are the ultimate and challenging limits to reach. Hence, the traffic upper bounds coupled with the anticipated levels of data compression can provide good estimates of the required broadband network capacity. It is also important to understand how many broadband devices we may find in an average household in the future. It is reasonable to assume that there will likely be only one large screen with a very high resolution in the household which will then become the main driver of traffic to the residential subscribers. However, many other devices at home will also have broadband connection and will be used for video viewing.

We have to consider that, in the future, video streaming may be, at least in some instances, replaced by a full initial download of the whole multimedia file before its replay. The compression levels and progress in the state-of-the-art compression methods have significant impact on the required network bandwidth. The large bandwidth of NGN will require less compression and, at the same time, provide better video quality. The current trend is to make applications more interactive and personalized. The existing compression methods such as MPEG-4 are insufficient for the stringent latency requirements of the interactive video applications, so new compression algorithms will have to be developed. Moreover, in future multimedia applications with video streaming being the key integral component, the users will be in charge to choose what to see, zoom-in on demand, change viewing angles and focal distances, and go back in time, and all this will be happening in real time with fast response and negligible latency.

The future video will be multi-view (the exact definition is unclear at the moment) with large content redundancy among the views which will allow good levels of compression. 
However, since the bandwidth is not for free, the users are unlikely to try to maximize their bandwidth use. Furthermore, the multimedia broadcast channels are likely to be shared by the viewers. The experience shows that the number of such channels rarely exceeds the number of users per household. Furthermore, due to large content redundancy and correlations, the traffic peak values do not add up linearly with the number of views. A simple adding up of traffic flows is a very loose upper bound, and more realistic is to use statistical summation (i.e. expectation or the average weighted by the probabilities). It is unlikely that parallel video streams would be sent at the same time to any household except at times of channel switching when the new channel has to be buffered first, so that at this time traffic will peak. The response times of channel switching need to be comparable to the time it takes for the user to realize that the channel has changed (about $1 \mathrm{~s}$ ).

\section{Drivers of future applications and services}

The important networking topics relevant to long-term traffic modelling are the services for user-created contents, the targeted advertising, and the related economies of the Internet. Some examples of the current rapidly expanding services are as follows: network virtualization, multicast and Pt-Pt delivery of multimedia (e.g. IPTV), online gaming, virtual reality and immersive environments, and localization-aware services. The future of gaming will likely change since new client (gaming) terminals are now being introduced to the market. Human-to-machine (H2M), M2H, M2M and H2H communications are another emerging service type.

The current trend to providing services in the broadband networks is to use bandwidth partitioning with dedicated bandwidth allocations. One example of this trend is Flexgrid [14]: the network bandwidth is dynamically allocated based on the current demand. In the area of wireless networks, small cells are currently being aggressively deployed with the number of femtocells expected to increase the number of macrocell base stations early in 2013. Since small-cell base stations such as femtocells are heavily relying on backhauling via broadband networks, the mobile traffic off-load may significantly contribute to overall broadband traffic. Another significant and rapidly increasing contributor to broadband traffic volumes are the software downloads and upgrades. It is therefore of interest to explore methods for optimizing the software delivery that can reduce traffic in the core network. For example, considering the concept of cloud computing, the computing power can be alternatively distributed at the network edges. Thus, cloud computing and data storage are likely to evolve to be provided partly centrally in the cloud and partly distributed at the network edges. These services will affect the upstream and downstream traffic symmetry.

\subsection{Enhanced personal communications}

At present, $\mathrm{H} 2 \mathrm{H}$ communications over broadband networks rely mainly on email, online chat (e.g. MSN) and audio/video calls (e.g. Skype). It is expected that these services will be gradually combined into one integrated and highly flexible application for online (real-time) as well as offline (leave-amessage) communications. Moreover, everyone will be assigned a universal unique ID or a personal account. Most $\mathrm{H} 2 \mathrm{H}$ messages are likely to be multimedia with embedded video and collections of high-resolution images and sounds. The current video technologies are being evolved towards being capable to fully exploit the potential limits of human sighting such as stereoscopic and $3 \mathrm{D}$ viewing and the capability to sense the direction the person is looking at and at which object he/she is focusing attention. Ultimately, the holographic video of the scene may be transmitted. Furthermore, the availability of additional senses will enhance and change the applications for human communications as we know them today. The broadband network users will be able to experience full-extent virtual reality with holographic images and sounds, touch and smell feelings, perhaps even enriched with the taste. Such new rich multimedia communications will be used extensively by social networking and gaming applications, and more importantly, they will incur much higher bandwidth requirements than their current versions.

\subsection{Web content customization}

Majority of contents in 20 years time are going to be generated by the broadband subscribers in their premises. Many applications and services on the broadband networks are becoming gradually highly personalized which will contribute to increased traffic variations. The search engines have evolved to be more intelligent with optimized presentation of the search results. The multimedia will become searchable to the extent that is now only possible for the text-based contents. The applications will be getting a lot smarter and provide a high level of interactivity. Future traffic will be much more affected by attributes such gender, age, emotional state, ethnical background and other such factors. This development is already evident in Japan where multiple sensors are exploited to collect and analyse data for advertising purposes [25]. These developments are further supported by the progress in artificial intelligence and discovery informatics [13] which are playing increasingly important roles in the creation of fully customized contents. Furthermore, it is expected that the broadband networks will be used much more efficiently, for example, by providing the contents in several multi-resolution descriptions chosen for given context and scenario. These developments require accurate predictive models of the users' behaviour and their intention. 


\subsection{Internet of Things (IoT) and machine communications}

Privacy is one of the top research, ethical and legal issues of the current Internet. The trend is to assign an ID not only to all network hosts but also to all network processes, activities and transactions. Home automation has been established to control lighting, heating, ventilation, air conditioning, security systems, home robots and appliances, and many other home systems including the home networks for distribution of audio and video in the households [37]. There is a strong emerging trend to embed broadband network connections into all home devices to enable their remote control over the Internet. The IoT and M2M communications (where devices and/or software components communicate) [11] are expected to increase the bandwidth demand. However, it is unlikely that the IoT and M2M communications will significantly affect the broadband traffic outward/inward of the households since most of this traffic will remain within the home network boundaries. The M2M communications can be also found in cars where sensors are frequently used to aid the car maintenance, to inform the developers [35] and to control car settings through dedicated applications [15]. In addition, the M2M communications are used for the electricity, gas and water utility metering in building the smart grids [33], and there are many other emerging applications. On the other hand, the video surveillance applications for increased safety and security are becoming very attractive, and, unlike the locally constrained M2M communications (used at home and in-car networks), they are likely to require significant additional bandwidth. Such applications are expected to grow rapidly and will include different kinds of sensors for automated control of machines. One of the distinct features of using sensors is that they will become almost ubiquitous, but more importantly, they will represent permanent traffic sources possibly requiring dedicated broadband connections which can generate large aggregated traffic over time. This will change requirements on the broadband network design in order to accommodate such dedicated links.

\subsection{Cloud computing and remote processing}

There is a noticeable increase of demand for cloud computing applications [20], which is also driven by proliferation of portable devices with limited computing power and storage [12]. Today, cloud computing includes solutions for delivering hardware and software resources as a service or platform over the broadband networks [29]. For instance, the handheld devices may be used as terminals to access extensive centralized computing resources. The future terminals will have enhanced human-computer interfaces; at minimum, they will be equipped with touch screen, high-resolution display, cameras and other sensors. Alternatively, the computing resources can be deployed or distributed at the network edges which may have some salient benefits. Consequently, cloud computing will change the structure of broadband networks. The related standardization efforts and developments in improving the security and trust of cloud computing are contributing to its acceptance. Furthermore, it is already observed that online storage services are generating a large amount of traffic which can be expected to only increase. Large amounts of data from ubiquitous sensors, other measuring campaigns and, particularly, scientific experiments generate truly massive amounts of data to be stored online in large databases. The data storage and access to such databases is likely to generate large traffic volumes. Thus, the bandwidth requirements of cloud computing and remote processing services are expected to far exceed those of other daily used services (e.g. WWW browsing).

\subsection{Education and work online}

Classroom-based lecturing is becoming an obsolete form of educating students. Traditional classroom lectures are now being enhanced or even, in some cases, replaced by online learning methods. There are many case studies clearly demonstrating this trend. We envision that high-quality interactive video streaming links to join students from anywhere around the world into virtual classrooms and virtual labs will be a norm in 20 years time. Online education can be further enhanced by the use of remote controllers including robots. A very similar discussion is applicable to working online supported by emergence of virtual offices and even virtual enterprises. Hence, education and work online will be significant drivers of future broadband traffic.

\subsection{Network architectures}

The broadband networks today are mainly concerned with delivering traffic to residential users. In 20 years, the demand for broadband services will become truly ubiquitous. In addition to the residential (home) and enterprise access, the broadband access will be required in public areas and spaces such as parks, streets, bus stops, shopping malls, restaurants, in cars and buses, etc. Majority of this broadband access will be realized wirelessly; however, it is very likely that backhaul traffic will have to be collected by wired networks in order to be cost-effective and in order to provide the sufficient bandwidth for such extremely large aggregated traffic. We believe that this is the main research direction when considering opportunities for significant investments in future broadband networks, especially in 20 years time. Inevitably, such network developments will be happening in the new market environments and with new business models. The future broadband networks will require different topology and architecture designs as well as different network management strategies in order to provide truly ubiquitous broadband access everywhere. For example, traffic will be automatically 
re-routed to most efficiently exploit the available instantaneous network transport capacity. In addition, new applications and services can be developed that are more aware of the broadband network state and that can adapt their parameters. In summary, the broadband network infrastructure is a tradeoff between the transport capacity and its implementation and operational cost. It is expected that the capacity will remain the main driver in the near future; however, at some point within the next 20 years, the bandwidth demand may saturate, and the cost factors may dominate the broadband network developments [41].

\section{Traffic volumes of video streaming}

As discussed above, applications and services with embedded video streaming will be the dominant driver of traffic growth in future broadband networks. The key parameters of video streaming are as follows: screen size, resolution, colour depth, frame rate, achievable compression and statistical multiplexing of streams [4]. Our investigation will consider high-resolution (definition) video services (i.e. the number of horizontal pixels being $4 \mathrm{~K}$ or even $8 \mathrm{~K}$ ) and the opportunities for significantly improving video quality.

There are several methods how to provide 3D video resulting in 30-80\% overhead compared to the base 2D video. The expected peak rates of future video are as large as $200 \mathrm{megabits} / \mathrm{s}(\mathrm{Mb} / \mathrm{s})$. For example, Youtube, Netflix and similar other services constitute highly compressed video streams (rates about $1 \mathrm{Mb} / \mathrm{s}$ ) whereas future IPTV will be of much higher quality $(8-16 \mathrm{Mb} / \mathrm{s}$ or even $22-30 \mathrm{Mb} / \mathrm{s})$. The take-up rate (i.e. rate of adding new customers) is another key parameter to consider not only for evaluations of traffic but also for cash-flow modelling, e.g. Version reports 25-35\% take-up rates. Assuming the logistic curve [39], the take-up rate grows in the first 2-3 years followed by a linear growth in the intermediate years and the final decline in the last few years. Next, we will summarize the existing and expected future video streaming methods and their bandwidth requirements.

\section{$4.12 \mathrm{D}$ video streaming}

Most of today's 2D video streaming methods use either standard definition (SD) or high definition (HD) format. The minimum and maximum bandwidth requirements of the SD and HD video streaming with MPEG-2 and MPEG-4 compressions, respectively, are given in Table 1 [23].

\section{$4.23 \mathrm{D}$ video streaming}

The 3D video technology is still under active development and standardization activities. There are different methods for
Table 1 The bandwidth requirements for 2D video streaming

\begin{tabular}{lll}
\hline 2D video format & $\begin{array}{l}\text { Minimum } \\
\text { bandwidth }(\mathrm{Mb} / \mathrm{s})\end{array}$ & $\begin{array}{l}\text { Maximum } \\
\text { bandwidth }(\mathrm{Mb} / \mathrm{s})\end{array}$ \\
\hline SD MPEG-2 & 2 & 5 \\
SD MPEG-4 & 1.5 & 2 \\
HD MPEG-2 & 15 & 20 \\
HD MPEG-4 & 5 & 10 \\
\hline
\end{tabular}

displaying and encoding 3D video. Some of them are already established while others have just been introduced. The ultimate aim of 3D video is to produce static and, later on, also moving holographic pictures. The main factors influencing $3 \mathrm{D}$ video development are the implementation and computing complexity, availability of network bandwidth and ultimately adoption by the consumers. Thus, the main players in adoption of 3D video services are the ISP, network infrastructure providers, TV equipment manufacturers, content providers and subscribers. For example, Philips started to develop an auto-stereoscopic TV to have been launched at the end of 2011, but then, this project was cancelled due to slow adoption of $3 \mathrm{D}$ video by the customers [27]. On the other hand, Toshiba, Samsung, Sony and Panasonic launched their autostereoscopic TV in the past 2 years $[34,36]$. Toshiba makes further investments into developing higher resolution 3D TV sets aiming to provide simultaneous $3 \mathrm{D}$ views which are more than any other available TV content of today [44].

The 3D video technologies can be classified into two main classes: 3D video with added depth perspective and 3D multiview video. The first approach is relatively well established by now, and it uses stereoscopic display with viewing glasses or with parallax barriers. The second approach uses autostereoscopic display without any need for viewing glasses. We next review the common 3D video encoding formats.

\subsubsection{D-plus-depth $(2 D+z)$ coding}

$2 \mathrm{D}+\mathrm{z}$ coding is one of the established encoding formats for $3 \mathrm{D}$ stereoscopic displays. The 3D view is achieved by adding depth map details into the conventional 2D images. This 3D encoding represents about 10-20\% overhead compared to the conventional $2 \mathrm{D}$ format.

Table 2 The bandwidth consumption per future 3D encoding stream

\begin{tabular}{lll}
\hline Coding scheme & $\begin{array}{l}\text { Minimum } \\
\text { bandwidth }(\mathrm{Mb} / \mathrm{s})\end{array}$ & $\begin{array}{l}\text { Maximum } \\
\text { bandwidth }(\mathrm{Mb} / \mathrm{s})\end{array}$ \\
\hline $2 \mathrm{D}+\mathrm{z}$ & 6 & 12 \\
MVC (8 views) & 52 & 144 \\
MVD (3 views+depth) & 23 & 60 \\
\hline
\end{tabular}


Table 3 The bandwidth demand upper bounds

\begin{tabular}{lllllllll}
\hline Year & $\begin{array}{l}\text { HD } \\
\text { MPEG-4 }\end{array}$ & 2D+z & $\begin{array}{l}\text { MVC: } \\
\text { 2 views }\end{array}$ & $\begin{array}{l}\text { MVC: } \\
\text { 4 views }\end{array}$ & $\begin{array}{l}\text { MVC: } \\
8 \text { views }\end{array}$ & $\begin{array}{l}\text { MVD: 3 } \\
\text { views+depth }\end{array}$ & $\begin{array}{l}\text { Total } \\
\text { (Mb/s) }\end{array}$ & $\begin{array}{l}\text { YoY } \\
\text { growth (\%) }\end{array}$ \\
\hline 2012 & 4 & & & & & & 40 & \\
2016 & 4 & & & & 48 & 5 \\
2020 & & 4 & & & & 144 & 32 \\
2024 & & & 4 & & & 288 & 19 \\
2028 & & & & 4 & & 576 & 19 \\
2032 & & & & 4 & 1 & 636 & 3 \\
\hline
\end{tabular}

\subsubsection{Multi-viewpoint coding (MVC)}

MVC is a relatively new 3D encoding format with the initial standard launched by ITU in 2009 as H.264/AVC. The main idea is to record and send multiple viewpoints together and then reconstruct these viewpoints as single 3D images. Assuming that there is no compression involved, the required bandwidth is upper-bounded as a product of the number of multi-views (recommended to be eight for industrial uses) and the bandwidth required for a single view [45]. The required bandwidth for the MVC encoding is increased by about 30 $80 \%$ per viewpoint over the conventional $2 \mathrm{D}$ singleviewpoint images.

\subsubsection{Multi-viewpoint plus depth (MVD)}

Since the MVC technique requires a relatively large number of multi-views, and thus, it has large bandwidth consumption, the MVD technique has been introduced to combine a depth map with MVC to reduce the required number of multi-views. Typically, the required number of multi-views for MVD is three in order to achieve the same viewing experience. This $3 \mathrm{D}$ video encoding format is still under active research [30, $38,46]$.

Assuming the HD MPEG-4 video encoding, Table 2 provides the upper and lower bounds of the bandwidth requirements for different 3D video technologies. Due to very large bandwidth consumption of MVC with eight views, the number of views for MVC is expected to grow gradually, so that it can be accommodated in the available bandwidth.
It is expected that the bandwidth requirements due to introduction of 3D video will be suddenly increased, and then this demand will be reduced with development of better video encoding formats and improved compression methods. This situation occurred previously with introduction of $2 \mathrm{D}$ video. However, there is still lack of $3 \mathrm{D}$ video standards, so the actual bandwidth requirements may be eventually different from those presented in Table 2. The 3D technology is expected to also have a major impact on online gaming, (enhanced) social networking, virtual worlds and other applications that are using video streaming [18]. Thus, video streaming will dominate and possibly reshape traffic of many applications and services. In the near future, the impact of $3 \mathrm{D}$ video on average traffic will be moderate; however, its impact on peak values will be much more noticeable. These developments encourage display manufacturers to develop new $3 \mathrm{D}$ viewing equipment and technologies.

\section{$520+$ years broadband traffic forecast}

We consider a case study of broadband traffic of residential subscribers per household between the cable modem and the optical splitter just outside the customer premises. Aggregated traffic to a local exchange or to a metro node then scales directly with the number of premises and the number of splitter branches. Since the aggregation effectively corresponds to averaging, such traffic will have smaller variations. As discussed in the previous section, we can assume that 3D video streaming (increasingly embedded in other applications)
Table 4 The bandwidth demand lower bounds

\begin{tabular}{lllllllll}
\hline Year & $\begin{array}{l}\text { SD } \\
\text { MPEG-4 }\end{array}$ & $\begin{array}{l}\text { HD } \\
\text { MPEG-4 }\end{array}$ & $\begin{array}{l}\text { 2D+z } \\
\text { 2 views }\end{array}$ & $\begin{array}{l}\text { MVC: } \\
\text { 4 views }\end{array}$ & $\begin{array}{l}\text { MVD: } \\
\text { 3 views+depth }\end{array}$ & $\begin{array}{l}\text { Total } \\
\text { (Mb/s) }\end{array}$ & $\begin{array}{l}\text { YoY } \\
\text { growth (\%) }\end{array}$ \\
\hline 2012 & 1 & & & & & 1.5 & \\
2016 & 1 & & & & 5 & 35 \\
2020 & & & & & & 6 & 5 \\
2024 & & & 1 & & & 13 & 21 \\
2028 & & & & 1 & & 26 & 19 \\
2032 & & & & 1 & 1 & 49 & 17 \\
\hline
\end{tabular}


Table 5 The assumed average usage hours per day

\begin{tabular}{lllllll}
\hline Age & $\begin{array}{l}\text { Video } \\
\text { streaming }\end{array}$ & $\begin{array}{l}\text { Virtual } \\
\text { worlds }\end{array}$ & $\begin{array}{l}\text { Online } \\
\text { gaming }\end{array}$ & $\begin{array}{l}\text { Online } \\
\text { education } \\
\text { and working }\end{array}$ & $\begin{array}{l}\text { Other } \\
\text { traffic }\end{array}$ & $\begin{array}{l}\text { Total usage } \\
\text { hours/day }\end{array}$ \\
\hline$>18$ & 1.5 & 1 & 0.5 & 4 & 4 & 11 \\
$14-18$ & 2 & 2 & 1 & 5 & 5 & 15 \\
$6-10$ & 1 & 0.5 & 2.5 & 0.5 & 0.5 & 5 \\
\hline
\end{tabular}

will dominate the bandwidth demands in NGN which will be estimated separately for the downstream and the upstream.

\subsection{Download bandwidth requirements}

The 3D video encoding standards are launched every 3 years [42]. It takes about one additional year for the $3 \mathrm{D}$ video codec to become considered by wider markets, so we assume that a new 3D video format is introduced every 4 years. Although the number of parallel video streaming channels is likely to be increasing in the future with the introduction of new multimedia applications, we assume that at any time each household is most likely consuming one single video stream. The traffic upper and lower bounds are obtained assuming video at high quality (e.g. high-definition TV) and at minimum quality (e.g. small-screen TV), respectively. These bounds are given in Tables 3 and 4 including the calculated YoY traffic growth rates which are the key parameter for dimensioning the broadband networks. The upper bound shows good approximation of the logistic curve of traffic demand which saturates in the last 4 years of the 20 -year period considered. The spread between the upper and lower bounds could be reduced by assuming more realistic conditions.

\subsection{Upload bandwidth requirements}

Upstream traffic is expected to grow due to development of new interactive multimedia as well as non-interactive and/or non-multimedia applications; however, the expected growth rate in the upstream will be smaller than that in the downstream. The multimedia applications requiring significant uplink bandwidth are those for interactive communications with embedded video. The cameras capable of recording 3D video are likely to become available within the 20 -year horizon. The upload of $3 \mathrm{D}$ videos to multimedia or storage servers will

Table 6 The usage probabilities of broadband applications

\begin{tabular}{llll}
\hline Age & $P_{1}$ & $P_{2}$ & $P_{3}$ \\
\hline$>18$ & 0.458 & 0.636 & 0.364 \\
$14-18$ & 0.625 & 0.67 & 0.33 \\
$6-10$ & 0.208 & 0.9 & 0.1 \\
\hline
\end{tabular}

contribute significantly to the uplink bandwidth demands even though these uploads could be scheduled for times when the uplink bandwidth becomes available (e.g. overnight or in early morning hours). Furthermore, as discussed above, new M2M communications and other emerging applications and services will make broadband traffic generated at the subscriber's premises to appear peakier with large instantaneous variations. Consequently, the ratio of the downlink to uplink traffic volumes in today's broadband connections being 10:1 will be much more balanced in future broadband networks [21]; this ratio may eventually become $1: 1$ even though it is difficult to predict how soon this will happen.

In order to gain a first insight into traffic variations in the residential households, we assess how likely or how often traffic delivered to the households is going to reach the previously computed upper bounds. We assume the average usage hours for different applications and user groups as shown in Table 5 [31]. We then calculate the probabilities $P_{1}, P_{2}$ and $P_{3}$ corresponding to the probability of accessing the broadband network, the probability of using some multimedia service and the probability of using other non-multimedia applications, respectively (see Table 6). In particular, the probability that all family members (in all age groups) use multimedia with embedded 3D video streaming at the same time and independently from each other is only $0.7 \%$. The probability that a single adult user consumes a single multimedia stream at any time is $29 \%$. In other words, the largest bandwidth peak due to multiplexing multiple independent video streams will occur with the probability $0.7 \%$ (i.e. approximately 1 out of 100 households at any time or, equivalently, for any household, for $1 \mathrm{~h}$ every $100 \mathrm{~h}$ ). On the other hand, approximately three out of ten households will generate traffic corresponding to a single video stream at any time, or, equivalently, each household will consume, on average, a single video stream for approximately one third of the day (i.e. 7.2 out of $24 \mathrm{~h}$ ).

\section{Conclusions}

The long-term traffic trends as well as the disruptive services that will spur new bandwidth demand in NGN were explored. The main public sources of broadband traffic data were provided. The important services and application drivers of traffic growth in future broadband networks were identified. These drivers included both multimedia (2D and $3 \mathrm{D}$ video) as well as non-multimedia (software upgrades and download, Internet storage) applications. Long-term traffic models to forecast traffic in the 20+-year horizon from today were investigated. In particular, the upstream and downstream traffic volumes in future NGN were obtained assuming upper bounds of broadband traffic between customer premises and the local exchange or metro node and assuming the most bandwidthdemanding services such as applications with embedded 
interactive $2 \mathrm{D}$ and $3 \mathrm{D}$ video streaming. The upstream versus downstream traffic volume ratio of 1:1 is likely to be reached in 20 years time; however, it is difficult to predict whether this may occur much earlier. The developed long-term traffic models can be connected to socio-economic models of NGN to evaluate the actual economic benefits, to map the potential revenues and to obtain the cash-flow curves of the network deployment employing different competing optical (or other) technologies.

Acknowledgement This work was funded by the Welsh Government and British Telecom plc as the Digital Wales Research Hub (DWRH) pilot project in the broadband traffic modelling and evaluation methods. The authors would like to also acknowledge the guidance provided by D. Payne and suggestions provided by N. Doran, D. Nesset and J. Seton.

Open Access This article is distributed under the terms of the Creative Commons Attribution License which permits any use, distribution, and reproduction in any medium, provided the original author(s) and the source are credited.

\section{References}

1. Al-Tamimi AK, Jain R, So-In C (2012) High-definition video streams analysis, modeling, and prediction. Adv Multimed 539396: $1-13$

2. Andrés L, Cuberes D, Diouf M, Serebrisky T (2010) The diffusion of the Internet: a cross-country analysis. Telecommun Policy 34(5-6): 323-340

3. Bauer S, Clark D, Lehr W (2009) Broadband microfoundations: the need for traffic data. In: Proceedings of beyond broadband access conference. New America Foundation, Washington, DC

4. Bo G (2011) How much bandwidth does Broadcast HD video use? Ciena Insights Blog. http://www.ciena.com/connect/blog/Howmuch-bandwidth-does-Broadcast-HD-video-use.html

5. British Telecom plc (2007) BT's view on future services. Video podcast. http://www.youtube.com/watch? $\mathrm{v}=\mathrm{VN} 3 \mathrm{hF} 8 \mathrm{dX} 8 \mathrm{TM}$

6. British Telecom plc (2011) BT's public statements on the real-world challenges of getting fibre to households. http://www.theregister.co. uk/2011/05/25/bt_fttp_trial_rollout_delayed/ and http://www. theregister.co.uk/2011/03/03/bt_milton_keynes fibre to the premises trial/

7. Brown P, Petrovic S (2011) A new statistical approach to estimate global file populations from local observations in the eDonkey P2P file sharing system. Ann Telecommun 66(1-2):5-16

8. Cho K, Fukuda K, Esaki H, Kato A, Murai J (2008) Observing slow crustal movement in residential user traffic. In: Proceedings of CAIDAWIDE Workshop, Marina del Rey, CA, USA. http://www.caida.org/ workshops/wide-casfi/0808/slides/residential user traffic.pdf

9. Cisco-VNI: Cisco Visual Networking Index (VNI). http://www. cisco.com/en/US/netsol/ns827/networking_solutions_sub_solution. $\mathrm{html}$

10. Crandall RW, Eisenach JA, Ingraham AT (2013) The long-run effects of copper-loop unbundling and the implications for fiber. Telecommun Policy 37(4-5):262-281

11. Crosby T (2013) How machine-to-machine communication works. $\mathrm{http}: / /$ computer.howstuffworks.com/m2m-communication.htm

12. Dediu H (2012) When will tablets outsell traditional PCs? Asymco. http://www.asymco.com/2012/03/02/when-will-the-tablet-marketbe-larger-than-the-pc-market/
13. Delgass WN (2004) Hollywood's 'minority report' becomes reality. Eng Manag J 6:5

14. Finisar (2013) Flexgrid technology for optical networks. http://www. finisar.com/technical-information

15. Ford Motor Company (2011) Ford teams with AT\&T to wirelessly connect new Ford Focus Electric. http://corporate.ford. $\mathrm{com} /$ news-center/press-releases-detail/pr-ford-teams-with-at26tto- 34274

16. FTTH-CE (2013) Fibre to the Home Council Europe. http://www. $\mathrm{ftthcouncil.eu}$

17. García AE, de Lope Rodríguez L, Hackbarth KD (2010) Application of cost models over traffic dimensioning with QoS restrictions. Ann Telecommun 65(3-4):135-144

18. George J (2006) Start thinking about 3 to 30 Gbps by 2030! Broadband Properties, No 42-47. http://www.broadbandproperties.com

19. Grote W, Grote A, Delgado I (2008) IEEE 802.11 goodput analysis for mixed real-time and data traffic for home networks. Ann Telecommun 63(9-10):463-471

20. Harris D (2011) Cisco: Cloud traffic fast approaching the zettabyte era. http://gigaom.com/2011/11/29/cisco-cloud-traffic-fastapproaching-the-zettabyte-era/

21. Harstead E (2011) Future bandwidth demands favors TDM PON, not WDM PON. In: Proceedings of optical fiber communication conference and exposition, Los Angeles

22. Hoernig S, Jay S, Neumann KH, Peitz M, Plückebaum T, Vogelsang I (2012) The impact of different fibre access network technologies on cost, competition and welfare. Telecommun Policy 36(2):96-112

23. ICF News (2013) How much bandwidth? Newsletter of International Cablemakers Federation. http://www.icf.at/en/6000/how_much_ bandwidth.html

24. Karagiannis T, Molle M, Faloutsos M (2004) Long-range dependence ten years of Internet traffic modeling. IEEE Internet Comput 8(5):57-64

25. Lah K (2010) Is 'Minority Report' becoming reality? CNN International Business News. http://business.blogs.cnn.com/2010/ 03/11/is-minority-report-becoming-reality

26. Madden G, Tan J (2007) Forecasting telecommunications data with linear models. Telecommun Policy 31(1):31-44

27. Martin N (2008) 3D television without the special glasses. The Telegraph (30 May). http://www.telegraph.co.uk/news/uknews/ 2054047/3D-television-without-the-specialglasses.html

28. MINTS: Minnesota Internet Traffic Studies (MINTS). Project homepage: http://www.dtc.umn.edu/mints

29. Monaco A (2012) A view inside the cloud: why the time is right for cloud computing to soar. The Institute, the IEEE news source. http:// theinstitute.ieee.org/technology-focus/technology-topic/a-viewinside-the-cloud

30. Na ST, Oh KJ, Lee C, Ho YS (2008) Multi-view depth video coding using depth view synthesis. In: Proceedings of IEEE international conference on circuits and systems, pp. 14001403

31. Ovum Europe (2012) The benefit to the Canadian economy from the wireless telecommunications industries: an economic impact assessment. Technical report for CWTA, pp. 1-50

32. Papagiannaki K, Taft N, Zhang ZL, Diot C (2005) Long-term forecasting of Internet backbone traffic. IEEE Trans Neural Netw 16(5): $1110-1124$

33. Rogers Communications (2011) Hydro-Quebec chooses Rogers for wireless connectivity of Smart Meter collectors. http://www. newswire.ca/en/story/731359/hydro-quebec-chooses-roger-forwireless-connectivity-of-smart-meter-collectors

34. Samsung (2010) Samsung learning resources: 3D TV. http://www. samsung.com/us/learningresources3D

35. Schwartz E (2003) When machines speak. InfoWorld Vol. 11.17.03, No 45 
36. Shimbun Y (2010) Toshiba to launch 3-D TVs that don't require glasses, Daily Yomiuri Online. http://www.yomiuri.co.jp/dy/ business/T100824003774.htm

37. Smarthouse (2013) Online retail store for home automation. http:// www.smarthousestore.co.uk

38. Smolic A, Kimata H, Vetro A (2005) Development of MPEG standards for 3D and free viewpoint video. In Proc SPIE Conf Opt East: Commun, Multimed Display Technol 6014:262-273

39. Stordahl K (2010) Market development up to 2015. Celtic project CP5-013, Deliverable D3.4, Telenor

40. Stordahl K (2011) Long-term penetration and traffic forecasts for the Western European fixed broadband market. In: Proceedings of 22nd European regional ITS conference, Budapest

41. Stordahl K (2008) Broadband demand and the role of new technologies. In: Proceedings of 13 th international telecommunications strategy and planning symposium, Budapest
42. Sullivan GJ (2005) Overview of international video coding standards (preceding H.264/AVC). ITU-T VICA Workshop, Geneva, Switzerland. http://www.itu.int/ITU-T/worksem/vica/docs/presentations/S0_P2 Sullivan.pdf

43. Thilakawardana D, Moessner K (2009) Traffic modelling and forecasting using genetic algorithms for next-generation cognitive radio applications. Ann Telecommun 64(7-8):535543

44. Toshiba 55ZL2 (2005) Review of Toshiba 3D TV. http://reviews. cnet.co.uk/tvs/toshiba-55zl2-review-50005001

45. Tytgat D (2009) New applications and opportunities in 3DTV IP distribution. In: Proceedings of Workshop VI: 3DTV: a distant perspective? Alcatel Lucent

46. Vetro A, Sehoon Y, Smolic A (2008) Towards a 3D video format for auto-stereoscopic displays. Technical report TR2008-057, Mitsubishi Electric Research Laboratories 